\title{
Moesin as a prognostic indicator of lung adenocarcinoma improves prognosis by enhancing immune lymphocyte infiltration
}

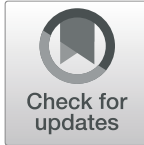

\author{
Yan-Qi Li, Zhi Zheng, Quan-Xing Liu, Xiao Lu, Dong Zhou, Jiao Zhang, Hong Zheng ${ }^{*}$ and Ji-Gang Dai*
}

\begin{abstract}
Background: Ezrin-radixin-moesin (ERM) have been explored in many cancer processes. Moesin, as its component, has also been found to play an important role in the prognosis of cancer patients, tumor metastasis, drug resistance, and others. Especially in regulating the immunity, but most results came from direct studies on immune cells, there is no clear conclusion on whether moesin has similar effects in tumor cells. And moesin has certain research results in many cancers in other aspects, but there are few about moesin in lung adenocarcinoma (LUAD).

Methods: We detect the expression of moesin in 82 LUAD and matched normal tissue samples by immunohistochemistry. Besides, for the pathological feature, we did a detailed statistical analysis. And with the help of various databases, we have done in-depth exploration of moesin's ability to enhance the extent of immune lymphocyte infiltration.
\end{abstract}

Results: Moesin is a poor expression in lung cancer tissues than the corresponding normal samples. And this phenomenon had a strongly associated with the prognosis and TNM stage of these LUAD patients. Moesin can enhance the infiltration of multiple immune lymphocytes in lung cancer. And this may be related to the interaction between moesin and various inflammatory molecules.

Conclusions: Moesin is a newly index for the prognosis of LUAD and improves the prognosis of LUAD patients by regulating a variety of inflammation-related molecules to enhance immune lymphocytes infiltration.

Keywords: Lung adenocarcinoma, Moesin, Infiltration, Inflammation, Immune lymphocytes, Poor prognosis

\section{Background}

Lung carcinoma is still the most common malignant tumor with the highest morbidity and mortality in China, and in recent years, LUAD has gradually developed into the highest rates in lung cancer [1]. Due to the difficulty of early diagnosis with the high risk of metastasis and recurrence, the treatment of LUAD patients is still a dilemma on clinic [2]. Therefore, to find a high sensitivity and specificity index to help the diagnosis and

\footnotetext{
* Correspondence: ziecoe@tmmu.edu.cn; daijigang@tmmu.edu.cn Department of Thoracic Surgery, Xinqiao Hospital, Army Medical University (Third Military Medical University), Chongqing 400037, China
}

mechanistic studies to guide the treatment of LUAD is necessary for the current clinical situation.

Moesin is a member of the highly homologous ezrinradixin-moesin (ERM) family of proteins that possess an $\mathrm{N}$-terminal four-point-one, ezrin, radixin, moesin (FERM) domain and C-terminal actin-binding domain. Research in recent years has shown that ERM plays an important role in various cancer-related processes such as driving tumor signals, maintaining cancer cell survival and cancer invasion and metastasis [3-7]. When further study the functions of its individual proteins, it is surprising that they seem to have some undiscovered effects in regulating immunity $[8,9]$. Study on moesin has

C C The Author(s). 2021 Open Access This article is licensed under a Creative Commons Attribution 4.0 International License, which permits use, sharing, adaptation, distribution and reproduction in any medium or format, as long as you give appropriate credit to the original author(s) and the source, provide a link to the Creative Commons licence, and indicate if changes were made. The images or other third party material in this article are included in the article's Creative Commons licence, unless indicated otherwise in a credit line to the material. If material is not included in the article's Creative Commons licence and your intended use is not permitted by statutory regulation or exceeds the permitted use, you will need to obtain permission directly from the copyright holder. To view a copy of this licence, visit http://creativecommons.org/licenses/by/4.0/ The Creative Commons Public Domain Dedication waiver (http://creativecommons.org/publicdomain/zero/1.0/) applies to the data made available in this article, unless otherwise stated in a credit line to the data. 
shown that it is closely related to the homeostasis and self-tolerance of $\mathrm{T}$ cell and B cell, as well as the outflow of these cells from secondary lymphoid organs [10-12]. Studies have also shown that moesin functioned in the production of regulatory $\mathrm{T}$ cells (Tregs) induced by TGF- $\beta$ by stabilizing type II (T $\beta$ RII) TGF- $\beta$ receptors on the $\mathrm{T}$ cell membrane [13]. In addition, a recent study pointed out that the dephosphorylation and inactivation of moesin in $\mathrm{T}$ cells was beneficial for the combination of T cells and APCs, thereby promoting the proliferation and activation of $\mathrm{T}$ cells [14]. These all suggest that how moesin regulates the body's immune capacity is a direction that worth exploring. However, although moesin has been found to make a difference in regulating immunity came from direct studies on immune cells, there is still no clear conclusion about what changes and mechanisms that moesin will cause for immune system in tumor cells.

But it should be pointed out that moesin has been found to have unique roles in other tumor-related processes except regulating immunity. It was considered an independent prognosis factor for many tumors, like oral squamous cell carcinoma and ER-positive breast cancer $[15,16]$. Besides, there found that $G$ protein-coupled receptor kinase GRK5 can phosphorylate moesin to promote prostate cancer metastasis and MiR-200 can promote cancer cell invasion through an unclear way which depended on moesin $[17,18]$. Interestingly, compared with changing the migration and invasion ability of a single cancer cell, studies have pointed out that Rab11 may trigger the collective migration of tumor cells by controlling the activity of moesin, but the more specific mechanisms still need further explored [19]. Furthermore, p53-microRNA 200-moesin axis was found to involve in the drug resistance in cancer cells, which showed the potential that regulating moesin to reverse tumor resistance [20]. In summary, these research results showed that moesin is an indicator that worth exploring in tumors, and in-depth study will be also beneficial for the tumor clinical diagnosis and treatment. But unfortunately, there was no relevant research report about moesin be found in LUAD. Therefore, it has great significance to explore the relation and reason between moesin and LUAD.

\section{Methods}

\section{Western blotting}

Paired tumor and normal lung tissues were dissected into $1-2 \mathrm{~mm}^{3}$ in $1 \mathrm{~mL}$ mix solution that contain radioimmunoprecipitation assay (RIPA) lysis buffer (Sangon Biotech) and Halt ${ }^{\mathrm{TM}}$ Protease and Phosphatase Inhibitor Cocktail (Thermo Fisher Scientifc, Waltham, MA, USA), tissue lysate was obtained by used a glass homogenizer. Then tissue lysate was centrifuged at $12,000 \mathrm{~g}$ for $5 \mathrm{~min}$ and supernatant was collected for western blotting. The concentrations of collection protein were measured by bicinchoninic acid (BCA) protein assay kit (Beyotime Biotechnology). The protein sample was electrophoresed on $10 \%$ sodium dodecyl sulfate-polyacrylamide gels and then transferred to an Immobilon PVDF membrane. The membrane incubated with primary antibody (Rabbit anti-moesin, ab52490, abcam; Rabbit anti- $\beta$-actin, 8457S, Cell Signaling Technology) for a night at $4{ }^{\circ} \mathrm{C}$ and then slightly shake with a horseradish peroxidase-conjugated secondary antibody (goat anti-rabbit IgG-HRP, sc-2004, Santa Cruz Biotechnology). The bands were soaked with chemiluminescence detection buffer (Takara, Shiga, Japan) and its intensity was detected by the corresponding software.

\section{Reverse transcription and quantitative real-time PCR}

Total RNA reverse transcribed by using PrimeScript ${ }^{\mathrm{m}} \mathrm{RT}$ reagent Kit with gDNA Eraser (TAKARA, Japan). The mRNA expression quantitative analysis of moesin was used to explore the difference between the lung adenocarcinoma specimens and the corresponding paracarcinoma tissues. The PCR reaction system $(25 \mu \mathrm{l})$ included $0.5 \mu \mathrm{l}$ of each primer (moesin and GAPDH), 12.5 $\mu$ SYBR Pre-mix Ex Taq TM II 2× (TAKARA, Japan), $10.5 \mu \mathrm{lddH_{2 }}$, and $1 \mu \mathrm{l}$ cDNA. The process of PCR was denaturation at $95{ }^{\circ} \mathrm{C}$ for $30 \mathrm{~s}$ and then amplification for 40 cycles contain $15 \mathrm{~s}$ at $95{ }^{\circ} \mathrm{C}$ and $50 \mathrm{~s}$ at $60{ }^{\circ} \mathrm{C}$, for each end of the circulation, there was a fluorescence acquisition. Using Illumina Eco software (Illumina, San Diego, USA) to detect the optical density of each PCR band. Primer sequence for moesin: FW: 5'-AAGGAC CGCAGTGAGGAGGAA

C-3', RV: 5'-CTTGGACTCATCTCTGGCATTGGC3'. Primer sequence for GADPH: FW: 5'-GGACCTGA CCTGCCGTCTAG-3'， RV: 5'-CCTGCTTCACCACC TTCTTG A-3'.

\section{Clinical patients}

The tissue microarray contains 90 LUAD samples and 82 matched para-carcinoma tissues. These patients were diagnosed at the Xinqiao Hospital, Army Military Medical University. A detailed follow-up was done from 2009-2014 and continued to 2017. However, 9 patients were lost follow-up in the process. All the patients had not received radiotherapy or chemotherapy before surgery. No patients with a history of immune system disorders.

\section{Immunohistochemistry and scoring}

The immunohistochemistry (IHC) assay of moesin was carried out with the Dako Envision FLEX+ system. After these tissue specimens went through section, dewaxing, and antigen retrieval, they wound incubated with the 


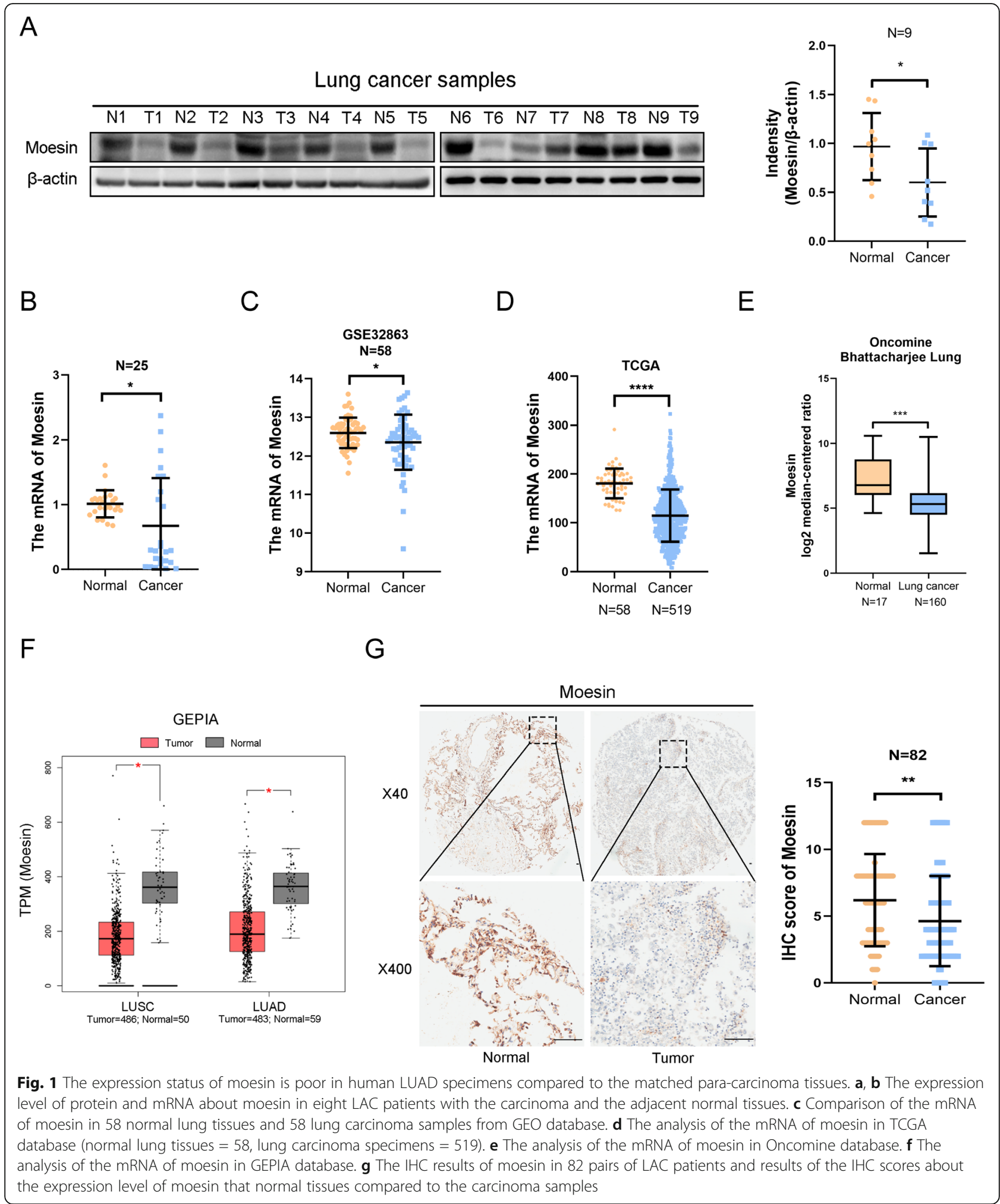


Table 1 Moesin expression in LUAD and adjacent normal mucosa

\begin{tabular}{llll}
\hline & Moesin (low) & Moesin (high) & $\boldsymbol{P}$ value \\
\hline Carcinoma & 72 & 18 & $P=0.001$ \\
Adjacent normal tissue & 46 & 36 & \\
\hline
\end{tabular}

antibody (Rabbit anti-moesin, ab52490, abcam) overnight at $4{ }^{\circ} \mathrm{C}$ and then with a HRP-conjugated antibody (Dako) at $37{ }^{\circ} \mathrm{C}$. At these slices were stained with 3diaminobenzidine (DAB) for $2 \mathrm{~min}$. The following were the scoring rules for the expression intensity: 0 , almost no staining; 1, mild staining; 2, medium staining; 3, strong staining. For the positive cell ratio: $0,0-20 \% ; 1$, $20-40 \%$; 2, 40-60\%; 3, 60-80\%; 4, 80-100\%. The final scores were the product of the two scores $(0,1,2,3,4$, $6,8,9$, or 12). Scores $0,1,2,3,4$, and 6 are low expression, and 8, 9, and 12 are high expression. And statistical $\mathrm{X}$-tile software was used to analyse the result.

\section{Statistical analysis}

All data were analysed using the IBM SPSS Statistics 19. Student's $t$ test was performed to compare the expression of moesin between lung cancer and normal tissues. The association between moesin expression and

Table 2 The clinical features of the LUAD specimens used in this study

\begin{tabular}{|c|c|c|c|}
\hline \multirow[t]{2}{*}{ Feature } & \multicolumn{3}{|c|}{ WHO grade } \\
\hline & $\mathrm{I}(n=9)$ & II $(n=66)$ & III $(n=13)$ \\
\hline \multicolumn{4}{|l|}{ Gender } \\
\hline Male & 2 & 34 & 13 \\
\hline Female & 7 & 32 & 0 \\
\hline \multicolumn{4}{|c|}{ Age at diagnosis } \\
\hline$<60$ & 4 & 29 & 5 \\
\hline$\geq 60$ & 5 & 37 & 8 \\
\hline \multicolumn{4}{|l|}{$T$ stage } \\
\hline$T_{1-2}$ & 7 & 54 & 10 \\
\hline$T_{3-4}$ & 2 & 14 & 3 \\
\hline \multicolumn{4}{|l|}{$N$ stage } \\
\hline$N_{x}$ & 2 & 12 & 1 \\
\hline$N_{0}$ & 6 & 25 & 5 \\
\hline$N_{1-3}$ & 0 & 32 & 7 \\
\hline \multicolumn{4}{|l|}{ TNM stage } \\
\hline I & 5 & 31 & 5 \\
\hline$\|$ & 5 & 18 & 4 \\
\hline III & 0 & 17 & 4 \\
\hline \multicolumn{4}{|l|}{ Location } \\
\hline Left & 6 & 27 & 6 \\
\hline Right & 3 & 38 & 7 \\
\hline
\end{tabular}

clinicopathological characteristics were evaluated by $\chi^{2}$ tests. Univariate and multivariate analysis were based on Cox proportional hazard regression models. KaplanMeier was used to explore the association between the moesin expression and the prognosis of lung cancer patients. $P<0.05$ was considered to indicate a statistically significant difference.

\section{Data mining and analysis}

We downloaded the expression data of moesin from GSE32863 in NCBI GEO, TCGA, Oncomine and GEPIA database, then using $R$ package (version 4.0.3) to observe its expression status in lung carcinoma and normal para-carcinoma tissues, all the results were tested with Student's $t$ test. For the LUAD patients, we performed a chi-test for all pathological features with the matched expression level of moesin. As for the prognosis of these patients, we conducted survival analysis using KaplanMeier method with moesin as the factor. Univariate and multivariate analysis were be used to detect the significance of moesin in the prognosis for LUAD patients. Data on the relationship between moesin and the degree of infiltration for various immune lymphocytes were

Table 3 The relationship between moesin expression and clinicopathological features of LUAD patients

\begin{tabular}{|c|c|c|c|}
\hline \multirow[t]{2}{*}{ Feature } & \multicolumn{2}{|l|}{ Moesin } & \multirow[t]{2}{*}{$P$ value } \\
\hline & High $(n=18)$ & Low $(n=72)$ & \\
\hline Gender & & & $P=0.034$ \\
\hline Male & $6(33.33 \%)$ & 44 (61.11\%) & \\
\hline Female & $12(66.67 \%)$ & $28(38.89 \%)$ & \\
\hline Age at diagnosis & & & $P=0.596$ \\
\hline$<60$ & $9(50.00 \%)$ & 31 (43.06\%) & \\
\hline$\geq 60$ & 9 (50.00\%) & 41 (56.94\%) & \\
\hline Location & & & $P=0.671$ \\
\hline Left & 7 (38.89\%) & 32 (44.44\%) & \\
\hline Right & $11(61.11 \%)$ & $40(55.56 \%)$ & \\
\hline$T$ stage & & & $P=0.039$ \\
\hline$T_{1-2}$ & $11(61.11 \%)$ & 60 (83.33\%) & \\
\hline$T_{3-4}$ & 7 (38.89\%) & $12(16.67 \%)$ & \\
\hline$N$ stage & & & $P=0.028$ \\
\hline$N_{0}$ & $11(73.33 \%)$ & 25 (41.67\%) & \\
\hline$N_{1-3}$ & $4(26.67 \%)$ & 35 (58.33\%) & \\
\hline TNM stage & & & $P=0.023$ \\
\hline 1 & $4(22.22 \%)$ & 37 (52.11\%) & \\
\hline$\|+\| \|$ & $14(77.78 \%)$ & 34 (47.89\%) & \\
\hline Histological grade & & & $P=0.309$ \\
\hline Well & $3(16.67 \%)$ & $6(8.57 \%)$ & \\
\hline Moderate & $11(61.11 \%)$ & 55 (78.57\%) & \\
\hline Poor & $4(22.22 \%)$ & $9(12.86 \%)$ & \\
\hline
\end{tabular}


from the TISIDB database. moesin co-expression molecules and degree scores were from coexpedia database, and the protein interaction network diagram was with the help of Cytoscape (version 3.7.1).

\section{Results}

\section{Moesin is poor expression in lung carcinoma}

In order to have a profound exploration about the expression level of moesin in lung cancer, we first explore its expression status in nine lung carcinoma samples with the matched para-carcinoma tissue. Whether the western blotting including its gray scale statistical results (Fig. 1a) or qPCR (Fig. 1b) indicated that both protein and mRNA of moesin is low-expressed in lung cancer tissue. To further confirm the reliability of the results, we analyzed the expression level of moesin in GEO (Fig. 1c), TCGA (Fig. 1d), Oncomine (Fig. 1e), and GEPIA (Fig. 1f) database by data mining and the results stay the same with our previous studies. In addition, we detected the protein level of moesin in 82 pairs of lung

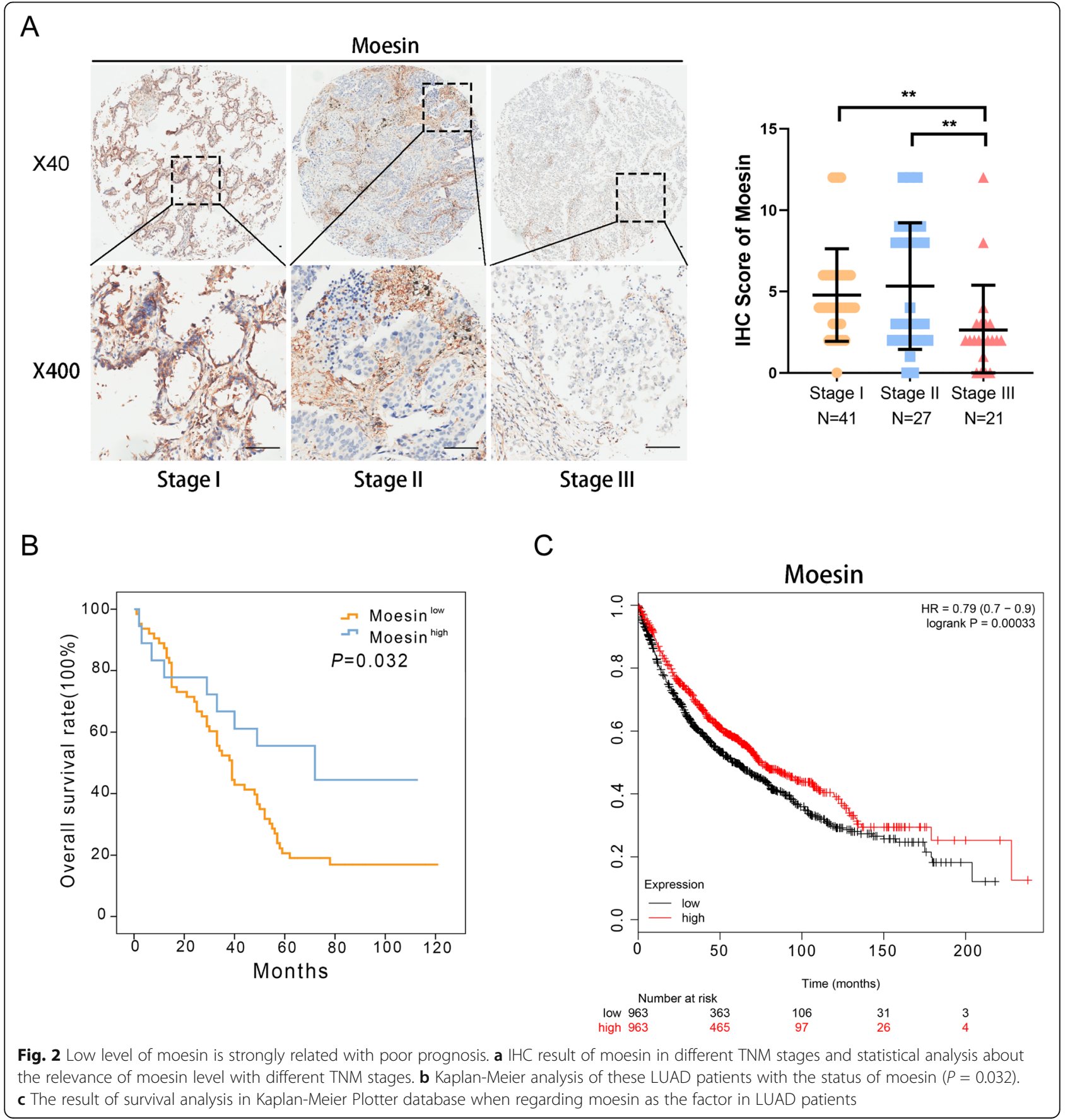


carcinoma specimens and adjacent tissues, the results showed that moesin is mainly settled on the membrane, and obviously, the para-carcinoma has a higher level $(43.9 \%, 36 / 82)$ than in the LUAD tissues $(20 \%, 18 / 90)$ (Fig. 1g, Table 1). Therefore, we found that moesin has a lower expression level in lung cancer than in paracarcinoma tissues.

\section{Moesin can be an index related to the prognosis of LUAD patients}

To identify whether the expression of moesin is associate with the clinical features of LUAD patients, and the clinicopathological data of these LUAD patients were shown in Table 2. Subsequently, we analyzed these data with statistical methods, and the results (Table 3) indicated that patients with high TNM stage seemed a greater probability to have a poor expression of moesin (Fig. 2a). Furthermore, in survival analysis, the LUAD patients with lower level of moesin showed a poor overall survival rate (Fig. $2 b, P=0.032$ ). The data from the Kaplan-Meier Plotter database demonstrated the same phenomena (Fig. 2c, $P<0.001$ ). More directly, the univariate analysis displayed the expression of moesin can be a unique indicator for the prognosis of LUAD patients $(\mathrm{HR}=0.471 ; 95 \%$ CI $0.231-0.960 ; P=0.023$, Table 4). All in all, these results strongly suggest that moesin can be deemed a prognostic factor for LUAD patients.

\section{Moesin can enhance the infiltration for a series of immune lymphocytes}

Next, we explored the possible mechanism for high expression of moesin to improve the prognosis of lung cancer patients. As studies in recent years have shown

Table 4 Univariate and multivariate analysis for overall survival in LUAD

\begin{tabular}{|c|c|c|c|c|}
\hline \multirow[t]{2}{*}{ Factors } & \multicolumn{2}{|l|}{ Univariate } & \multicolumn{2}{|l|}{ Multivariate } \\
\hline & HR $(95 \% \mathrm{Cl})$ & $P$ value & HR $(95 \% \mathrm{Cl})$ & $P$ value \\
\hline \multirow[t]{2}{*}{ Gender } & 1.288 & 0.326 & 1.009 & 0.977 \\
\hline & $(0.777-2.133)$ & & $(0.558-1.824)$ & \\
\hline \multirow[t]{2}{*}{ Age } & 1.023 & 0.930 & 0.812 & 0.446 \\
\hline & $(0.612-1.711)$ & & $(0.475-1.388)$ & \\
\hline \multirow[t]{2}{*}{ Location } & 1.084 & 0.757 & 1.016 & 0.955 \\
\hline & $(0.650-1.809)$ & & $(0.586-1.762)$ & \\
\hline \multirow[t]{2}{*}{ Moesin expression } & 0.471 & 0.038 & 0.424 & 0.023 \\
\hline & $(0.231-0.960)$ & & $(0.203-0.887)$ & \\
\hline \multirow[t]{2}{*}{ Grade } & 1.672 & 0.066 & 1.945 & 0.064 \\
\hline & $(0.966-2.897)$ & & $(0.962-3.935)$ & \\
\hline \multirow[t]{2}{*}{ TNM stage } & 1.891 & $<0.001$ & 1.899 & $<0.001$ \\
\hline & $(1.349-2.649)$ & & $(1.356-2.658)$ & \\
\hline
\end{tabular}

that moesin has immune modulatory functions in immune cells and it is still unclear whether moesin has similar abilities in tumor cells, these prompted us to be interested in whether moesin expressed in lung cancer tumor cells could regulate anti-tumor immunity. To this end, we made a preliminary analysis by the TISIDB database. Surprisingly, the results showed that whether in LUAD or lung squamous cell carcinoma (LUSC), moesin promotes the infiltration for a variety of immune cells including CD4+ T cells, CD8+ T cells, and DC cells (Fig. 3a). Further analysis showed that the expression level of moesin protein was significantly related to the degree of infiltration for these immune cells (Fig. 3b, c). These results fully indicate that promoting immune lymphocyte infiltration was the mechanism of moesin.

\section{Moesin regulates inflammation-related molecules to promote immune lymphocyte infiltration}

To further explored the specific mechanism of moesin promoting immune lymphocyte infiltration, we detected the coexpression degree of moesin with a variety of inflammation-related molecules in the coexpedia database and selected molecules with a score greater than 2 for enrichment (Table 5). The results showed that moesin has an obvious interaction relationship with these inflammation-related molecules (Fig. 4a), and importantly the results of GO enrichment and KEGG enrichment indicated that they mainly play a role in immunerelated processes in NSCLC cells (Fig. 4b). Further analysis for the expression data of LUAD patients in the TCGA database showed that moesin was significantly positively correlated with the expression of PECAM1, CSF2RB, WAS, SLA, CD40, and LCP1 (Fig. 4c). Meanwhile, the high expression of the 6 genes can significantly improve the prognosis of patients (Fig. 4d). And like moesin, the 6 genes can also indeed promote the infiltration of multiple immune lymphocytes (Fig. 4e). These suggest that moesin regulates the expression of a variety of inflammation-related molecules to promote immune lymphatic infiltration and thus improves the prognosis of lung cancer patients.

\section{Discussion}

For the low overall survival rate of LUAD in clinical because of its high recurrence ratio [21]. To find a highly specificity indicator for the poor prognosis and explore the mechanism to help the clinical treatment have important implications. Hereon, we found that moesin is obviously low-expressed in LUAD tissues than the matched para-carcinoma samples. Also, our results indicated that this phenomenon has an intense relation with the poor prognosis in clinical of LUAD. Further statistical analysis suggested that moesin can be used as a 
A

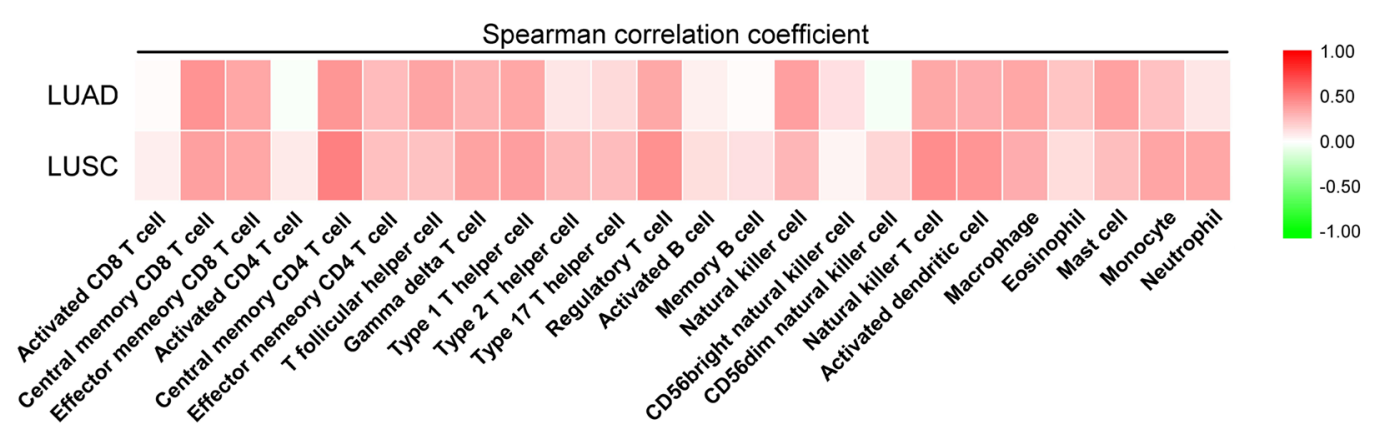

B

LUAD
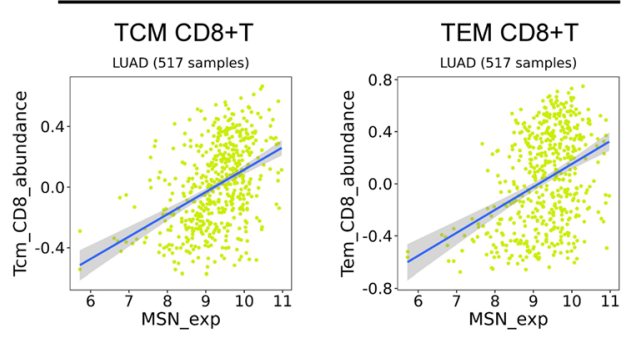

rho $=0.427, p<2.2 \mathrm{e}-16$

TCM CD4+T

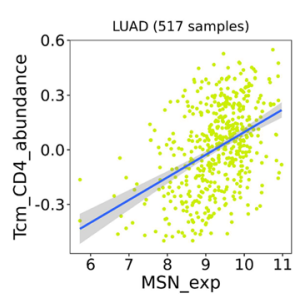

rho $=0.41, p<2.2 \mathrm{e}-16$

Activated DC

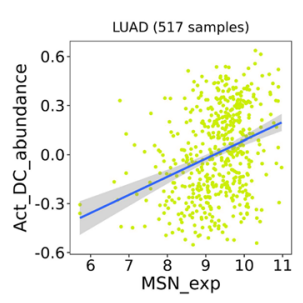

rho $=0.324, p=5.67 e-14$

NK

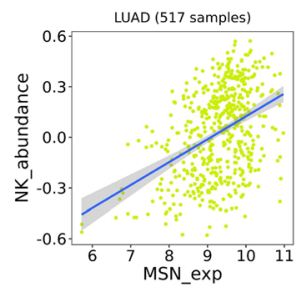

rho $=0.374, p<2.2 \mathrm{e}-16$ rho $=0.343, p=1.28 \mathrm{e}-15$

TEM CD4+T

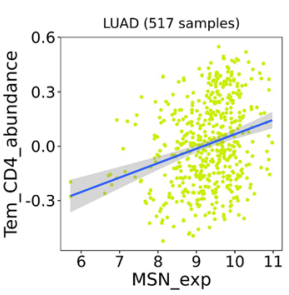

rho $=0.265, p=1.16 \mathrm{e}-09$

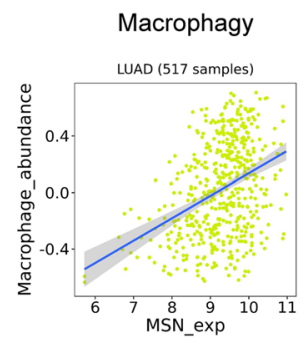

rho $=0.347, p=5.71 \mathrm{e}-16$

NKT

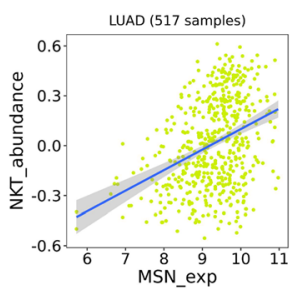

rho $=0.338, p=3.37 \mathrm{e}-15$
C

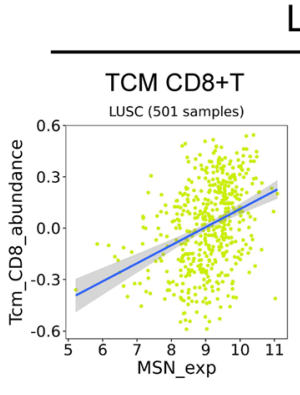

LUSC

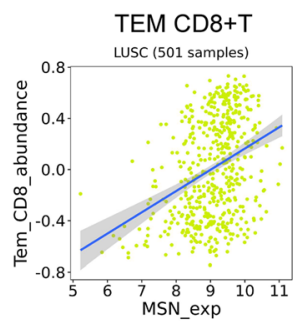

rho $=0.372, p<2.2 \mathrm{e}-16$

TCM CD4+T

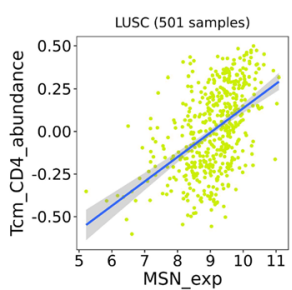

rho $=0.497, p<2.2 \mathrm{e}-16$

Activated DC

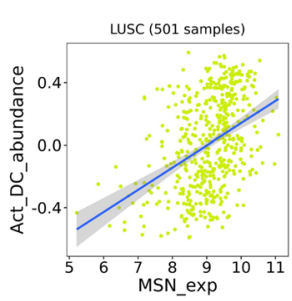

rho $=0.413, p<2.2 \mathrm{e}-16$

NK

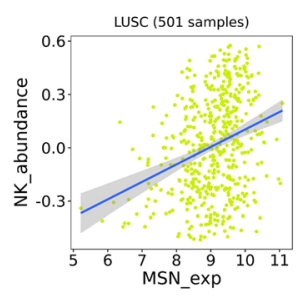

rho $=0.286, p=8.3 e-11$ rho $=0.345, p=2.29 \mathrm{e}-15$

TEM CD4+T

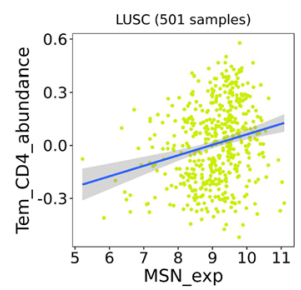

rho $=0.244, p=3.73 e-08$

Macrophagy

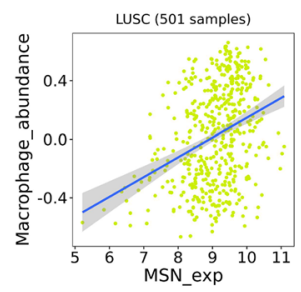

rho $=0.324, p=1.39 \mathrm{e}-13$

NKT

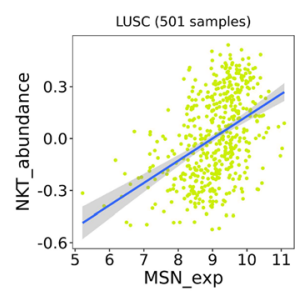

rho $=0.444, p<2.2 \mathrm{e}-16$

Fig. 3 (See legend on next page.) 
(See figure on previous page.)

Fig. 3 Moesin promotes the infiltration for a series of immune lymphocytes in LUAD and LUSC. a The heat map between moesin and the degree of infiltration for various immune lymphocytes in TISIDB database. $\mathbf{b}$ The expression of moesin and the degree of infiltration for various immune lymphocytes were significantly positively correlated in LUAD. c The expression of moesin and the degree of infiltration for various immune lymphocytes were significantly positively correlated in LUSC

Table 5 Co-expressed genes with MSN

\begin{tabular}{|c|c|}
\hline Gene symbol and name & LLS scores \\
\hline PECAM1 & 4.012 \\
\hline RAB31 & 3.434 \\
\hline PPP1R18 & 2.778 \\
\hline ENTPD1 & 2.749 \\
\hline CSF2RB & 2.704 \\
\hline RBMS1 & 2.692 \\
\hline ITGB2 & 2.661 \\
\hline QKI & 2.658 \\
\hline PTPRC & 2.654 \\
\hline CHST15 & 2.642 \\
\hline ST3GAL1 & 2.641 \\
\hline RASSF2 & 2.621 \\
\hline WIPF1 & 2.601 \\
\hline THEMIS2 & 2.567 \\
\hline CD53 & 2.551 \\
\hline RAC2 & 2.520 \\
\hline HCLS1 & 2.479 \\
\hline SRGN & 2.479 \\
\hline CHST11 & 2.473 \\
\hline HLX & 2.445 \\
\hline WAS & 2.375 \\
\hline PLEKHO1 & 2.331 \\
\hline SLA & 2.295 \\
\hline DOK3 & 2.281 \\
\hline RFTN1 & 2.262 \\
\hline GNB4 & 2.249 \\
\hline ETS1 & 2.227 \\
\hline SERPING1 & 2.214 \\
\hline GMFG & 2.203 \\
\hline ASAP1 & 2.184 \\
\hline GPR183 & 2.157 \\
\hline SAMSN1 & 2.155 \\
\hline FAM129A & 2.153 \\
\hline LY96 & 2.135 \\
\hline CD40 & 2.080 \\
\hline $\mathrm{ROBO} 1$ & 2.066 \\
\hline FAM49A & 2.020 \\
\hline CORO1A & 2.015 \\
\hline LCP1 & 2.011 \\
\hline
\end{tabular}

novel independent factor for the prognosis of LUAD patients.

For the specific mechanism of high expressed moesin to improve the prognosis of LUAD patients, in view of the fact that moesin has been found to regulate the body's own immunity in immune cells, we thought it may also have a similar effect in tumor cells. In fact, moesin has been found to be significantly upregulated in breast cancer, prostate cancer, pancreatic cancer, and other cancers $[17,22,23]$, but there were few reports on changes the upregulation will cause in cancer. Rituximab, which binds CD20 on B cells, is widely used clinically to treat $\mathrm{B}$ cell malignancies and current researches showed that its anti-cancer ability mainly relies on the ADCC effect of NK cells [8, 24, 25]. A specific study pointed out that when rituximab blocks CD20, moesin will be selectively recruited to the CD20 cap, leading to polarization of cancer cells, and this polarization increased the frequency of NK cells killing target cells through ADCC by $60 \%$ compared with the nonpolarization [26]. What is more, our results further showed that in lung cancer, moesin may not only promote the infiltration of NK cells. With the increasing of moesin expression, the degree of infiltration for various immune lymphocytes including central memory $\mathrm{T}$ (TEM), central memory $\mathrm{T}$ (TCM), activated $\mathrm{DC}$, and NKT cells increases significantly. And it is worth noting that moesin promotes the infiltration of TCM cells, which may indicate that moesin can indeed maintain the body's own immunity against tumor cells for a long time to improve the prognosis of cancer patients [27]. In general, these indicate that increasing the infiltration of immune lymphocytes by changing the polarity of cancer cells is only one mechanism, a more complete mechanism remains to be studied. However, there are still something interesting, a study in breast cancer indicated that the phosphorylation of moesin was necessary for programmed cell death-Ligand 1 (PD-L1) to stabilize on the cell membrane surface and silencing moesin can promote $\mathrm{T}$ cell activation in vitro and in vivo [28]. This suggests that in different cancers, the role of moesin may be different, research on different cancer models is conducive to the formulation of personalized clinical treatment plans.

For the fact that the activation of the body's immune capacity is usually accompanied by an inflammatory response, we have made a preliminary exploration on whether moesin promotes the infiltration of immune 


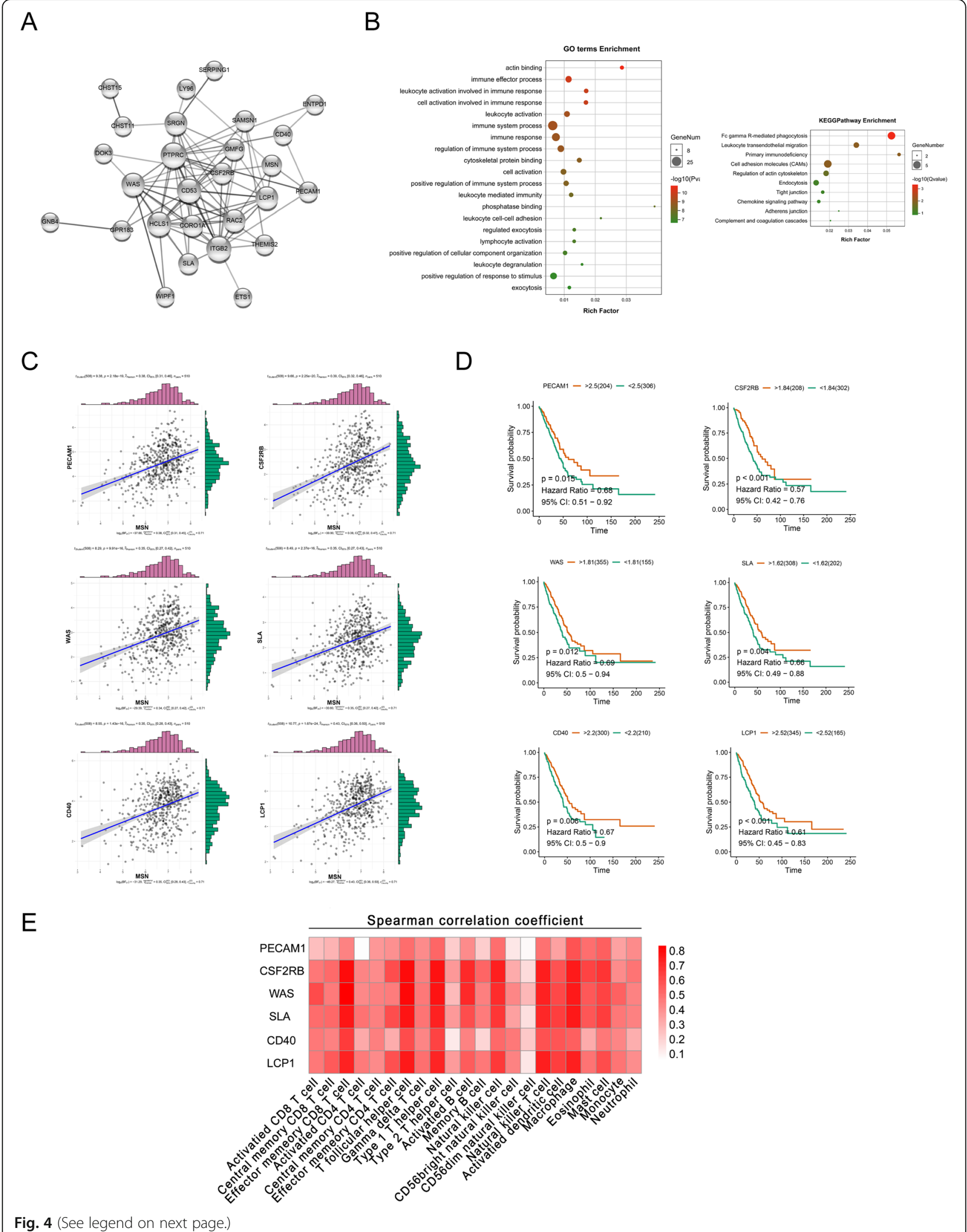

Fig. 4 (See legend on next page.) 
(See figure on previous page.)

Fig. 4 Moesin enhances immune lymphocyte infiltration by regulating a variety of inflammatory molecules. a Network diagram of protein interaction between moesin and inflammatory molecules with a co-expression score greater than 2. $\mathbf{b}$ GO enrichment and KEGG function enrichment results of moesin with these inflammatory molecules. c The expression correlation for moesin with PECAM1, CSF2RB, WAS, SLA, CD40, LCP1 in LUAD from TCGA database. $\mathbf{d}$ The relationship between the 6 genes and the prognosis of LUAD patients in TCGA. e Changes in the degree of immune lymphocyte infiltration caused by the 6 genes in LUAD from TISIDB database

lymphocytes by regulating inflammation-related signals. We initial queried the coexpression degree for moesin with a variety of inflammatory molecules in the coexpedia database and selected molecules with a coexpression score greater than 2 for follow analysis. The protein interaction network diagram showed that there was indeed a strong connection between moesin and these molecules, while GO enrichment and KEGG enrichment more directly indicated that they do have an important role in promoting the activation and migration of immune lymphocytes. This fully proved that moesin can improve the prognosis of lung cancer patients by regulating a variety of inflammatory molecules. We then further screened these inflammatory molecules, what is interesting is that we found that the 6 inflammatory molecules, PECAM1, CSF2RB, WAS, SLA, CD40, and LCP1, were not only highly positively correlated with moesin in expression, but also significantly improved the prognosis for LUAD patients in clinic. And the 6 molecules can also enhance the infiltration for a variety of immune lymphocytes like moesin, but there is no report on how moesin with the 6 molecules enhance the degree of immune lymphocyte infiltration in cancer. Specifically, the current researches showed that PECAM1 is a cell adhesion molecule required for leukocyte migration across the endothelium, and CSF2RB is a high-affinity receptor for granulocyte macrophage colony-stimulating factor [29]. SLA, CD40, LCP1, WAS may play an important role in the activation, migration, and positive sorting of $\mathrm{T}$ cells $[30,31]$. These may be a good hint for the subsequent study about the specific mechanism of moesin with these inflammatory molecules, but research still not be limited to these directions.

Besides, recent studies have shown that moesin may also play a role in tumor drug resistance. Inhibiting the expression of moesin can reduce the expression of $\mathrm{p}$-gp and BCRP proteins $[20,32]$ and reduce the efflux function of these proteins [33]. A more specific study pointed out that the reduction of moesin expression is mainly to reduce the expression of $\mathrm{p}$-gp in the membrane, indicating that moesin may be a molecule required for $\mathrm{p}$-gp to be anchored in the membrane, but the specific mechanism still needs to be further explored [34]. With clinical application value, moesin silencing restores the sensitivity to Doxorubicin of breast cancer cells [20]. Another study also pointed out that reducing the expression of moesin can increase the accumulation of methotrexate in cancer cells [35]. Interestingly, our study showed that high expression of moesin is beneficial for lung cancer patients. However, for drug resistance, current research showed that inhibiting moesin expression is related to reversing drug resistance. The connection and mechanism behind this are worthy of our further exploration in the future.

\section{Conclusions}

In conclusion, we found that in LUAD, the expression of moesin in cancer tissues was significantly lower than that in normal tissues, and this phenomenon was strongly correlated with the poor prognosis of patients. At the same time, our analysis showed that moesin might be a molecular marker to predict the prognosis of LUAD to guide clinical diagnosis and treatment. Further studies have shown that moesin may enhance the infiltration of immune lymphocytes in cancer by regulating a variety of inflammatory molecules, thereby improving the prognosis of LUAD patients. Our data provide a new insight into the treatment and development mechanism of human LUAD.

\section{Abbreviations}

ERM: Ezrin-radixin-moesin; LUAD: Lung adenocarcinoma; FERM: Four-pointone, ezrin, radixin, moesin; Tregs: Regulatory T cells; TRRIl: Type II TGF- $\beta$ receptors; LUSC: Lung squamous cell carcinoma; TEM: Central memory T; TCM: Central memory T

\section{Authors' contributions}

$J G D$ and $\mathrm{HZ}$ contributed substantially to the conception and design and gave the final approval of the version to be published. QXL and XL contributed to the analysis and interpretation of all data. DZ and JZ revised the article critically for important intellectual content. YQL and ZZ did the experimental and drafted the article. All authors read and approved the final manuscript.

\section{Funding}

This research is supported by National Science Foundation of China (81972190) and the Scienctifc Research Project of Undergraduate, Army (Third) Medical University (2019XBK48).

\section{Availability of data and materials}

The data sets during and/or analyzed during the current study are available from the corresponding author on reasonable request

\section{Declarations}

Ethics approval and consent to participate

This study was approved by the Ethical Committee of Xinqiao Hospital of the Army Military Medical University. We got the agreement and signed consent form of the patient reported in our paper.

Consent for publication

Not applicable. 


\section{Competing interests}

The authors declare that they have no competing interests.

\section{Received: 7 February 2021 Accepted: 3 April 2021}

\section{Published online: 10 April 2021}

\section{References}

1. Torre LA, Bray F, Siegel RL, Ferlay J, Lortet-Tieulent J, Jemal A. Global cancer statistics, 2012. CA Cancer J Clin. 2015;65(2):87-108. https://doi.org/10.3322/ caac.21262.

2. Do H, Kim D, Kang J, Son B, Seo D, Youn H, et al. TFAP2C increases cell proliferation by downregulating GADD45B and PMAIP1 in non-small cell lung cancer cells. Biol Res. 2019;52(1):35. https://doi.org/10.1186/s40659-0190244-5.

3. Luo Y, Zheng C, Zhang J, Lu D, Zhuang J, Xing S, et al. Recognition of CD146 as an ERM-binding protein offers novel mechanisms for melanoma cell migration. Oncogene. 2012;31(3):306-21. https://doi.org/10.1038/onc.2 011.244 .

4. Riecken LB, Zoch A, Wiehl U, Reichert S, Scholl I, Cui Y, et al. CPI-17 drives oncogenic Ras signaling in human melanomas via Ezrin-Radixin-Moesin family proteins. Oncotarget. 2016;7(48):78242-54. https://doi.org/10.18632/ oncotarget.12919.

5. Pore D, Bodo J, Danda A, Yan D, Phillips JG, Lindner D, et al. Identification of Ezrin-Radixin-Moesin proteins as novel regulators of pathogenic B-cell receptor signaling and tumor growth in diffuse large B-cell lymphoma. Leukemia. 2015:29(9):1857-67. https://doi.org/10.1038/leu.2015.86.

6. Kobori T, Harada S, Nakamoto K, Tokuyama S. Time-dependent changes in the activation of RhoA/ROCK and ERM/p-ERM in the increased expression of intestinal P-glycoprotein by repeated oral treatment with etoposide. J Pharm Sci. 2013;102(5):1670-82. https://doi.org/10.1002/jps.23503.

7. Li H, Zhang B, Liu Y, Yin C. EBP50 inhibits the migration and invasion of human breast cancer cells via LIMK/cofilin and the PI3K/Akt/mTOR/MMP signaling pathway. Med Oncol. 2014;31(9):162. https://doi.org/10.1007/s12 032-014-0162-x.

8. Gupta N, Wollscheid B, Watts JD, Scheer B, Aebersold R, DeFranco AL. Quantitative proteomic analysis of B cell lipid rafts reveals that ezrin regulates antigen receptor-mediated lipid raft dynamics. Nat Immunol. 2006;7(6):625-33. https://doi.org/10.1038/ni1337.

9. Pore D, Parameswaran N, Matsui K, Stone MB, Saotome I, McClatchey Al, et al. Ezrin tunes the magnitude of humoral immunity. J Immunol. 2013; 191(8):4048-58. https://doi.org/10.4049/jimmunol.1301315.

10. Serrador JM, Alonso-Lebrero JL, Del PM, Furthmayr H, Schwartz-Albiez R, Calvo J, et al. Moesin interacts with the cytoplasmic region of intercellular adhesion molecule-3 and is redistributed to the uropod of T lymphocytes during cell polarization. J Cell Biol. 1997;138(6):1409-23. https://doi.org/10.1 083/jcb.138.6.1409.

11. Serrador JM, Nieto M, Alonso-Lebrero JL, Del PM, Calvo J, Furthmayr H, et al. CD43 interacts with moesin and ezrin and regulates its redistribution to the uropods of T lymphocytes at the cell-cell contacts. Blood. 1998;91(12):463244. https://doi.org/10.1182/blood.V91.12.4632.

12. Hirata T, Nomachi A, Tohya K, Miyasaka M, Tsukita S, Watanabe T, et al. Moesin-deficient mice reveal a non-redundant role for moesin in lymphocyte homeostasis. Int Immunol. 2012;24(11):705-17. https://doi.org/1 0.1093/intimm/dxs077

13. Ansa-Addo EA, Zhang Y, Yang Y, Hussey GS, Howley BV, Salem M, et al. Membrane-organizing protein moesin controls Treg differentiation and antitumor immunity via TGF- $\beta$ signaling. J Clin Invest. 2017;127(4):1321-37. https://doi.org/10.1172/JCl89281.

14. Esen E, Sergin I, Jesudason R, Himmels P, Webster JD, Zhang H, et al. MAP4K4 negatively regulates CD8 T cell-mediated antitumor and antiviral immunity. Sci Immunol. 2020;5(45):eaay2245. https://doi.org/10.1126/ sciimmunol.aay2245

15. Yu L, Zhao L, Wu H, Zhao H, Yu Z, He M, et al. Moesin is an independent prognostic marker for ER-positive breast cancer. Oncol Lett. 2019:17:192133.

16. Barros F, Assao A, Garcia NG, Nonogaki S, Carvalho AL, Soares FA, et al. Moesin expression by tumor cells is an unfavorable prognostic biomarker for oral cancer. Bmc Cancer. 2018;18(1):53. https://doi.org/10.1186/s12885-01 7-3914-0.

17. Chakraborty PK, Zhang Y, Coomes AS, Kim WJ, Stupay R, Lynch LD, et al. G protein-coupled receptor kinase GRK5 phosphorylates moesin and regulates metastasis in prostate cancer. Cancer Res. 2014;74(13):3489-500. https://doi. org/10.1158/0008-5472.CAN-13-2708.

18. Li X, Roslan S, Johnstone CN, Wright JA, Bracken CP, Anderson M, et al. MiR200 can repress breast cancer metastasis through ZEB1-independent but moesin-dependent pathways. Oncogene. 2014;33(31):4077-88. https://doi. org/10.1038/onc.2013.370.

19. Emery G, Ramel D. Cell coordination of collective migration by Rab11 and Moesin. Commun Integr Biol. 2013;6(4):e24587. https://doi.org/10.4161/ cib.24587.

20. Alam F, Mezhal F, El HH, Nair VA, Aravind SR, Saber AM, et al. The role of p53-microRNA 200-Moesin axis in invasion and drug resistance of breast cancer cells. Tumour Biol. 2017;39:1393375030

21. Xue M, Tao W. Upregulation of MUC1 by its novel activator 14-3-3Z promotes tumor invasion and indicates poor prognosis in lung adenocarcinoma. Oncol Rep. 2017;38(5):2637-46. https://doi.org/10.3892/ or.2017.5948.

22. Fernando $H$, Martin TA, Douglas-Jones A, Kynaston HG, Mansel RE, Jiang WG. Expression of the ERM family members (ezrin, radixin and moesin) in breast cancer. Exp Ther Med. 2010;1(1):153-60. https://doi.org/10.3892/etm_ 00000025

23. Abiatari I, Esposito I, Oliveira TD, Felix K, Xin H, Penzel R, et al. Moesindependent cytoskeleton remodelling is associated with an anaplastic phenotype of pancreatic cancer. J Cell Mol Med. 2010;14(5):1166-79. https:// doi.org/10.1111/j.1582-4934.2009.00772.x.

24. Clynes RA, Towers TL, Presta LG, Ravetch JV. Inhibitory Fc receptors modulate in vivo cytotoxicity against tumor targets. Nat Med. 2000;6(4):4436. https://doi.org/10.1038/74704.

25. Cartron G, Dacheux L, Salles G, Solal-Celigny P, Bardos P, Colombat P, et al. Therapeutic activity of humanized anti-CD20 monoclonal antibody and polymorphism in IgG Fc receptor FcgammaRllla gene. Blood. 2002;99(3): 754-8. https://doi.org/10.1182/blood.V99.3.754.

26. Rudnicka D, Oszmiana A, Finch DK, Strickland I, Schofield DJ, Lowe DC, et al. Rituximab causes a polarization of B cells that augments its therapeutic function in NK-cell-mediated antibody-dependent cellular cytotoxicity. Blood. 2013:121(23):4694-702. https://doi.org/10.1182/blood-2013-02-482570.

27. Youngblood B, Hale JS, Ahmed R. T-cell memory differentiation: insights from transcriptional signatures and epigenetics. Immunology. 2013;139(3): 277-84. https://doi.org/10.1111/imm.12074.

28. Meng F, Su Y, Xu B. Rho-associated protein kinase-dependent moesin phosphorylation is required for PD-L1 stabilization in breast cancer. Mol Oncol. 2020;14(11):2701-12. https://doi.org/10.1002/1878-0261.12804.

29. Dasgupta B, Dufour E, Mamdouh Z, Muller WA. A novel and critical role for tyrosine 663 in platelet endothelial cell adhesion molecule-1 trafficking and transendothelial migration. J Immunol. 2009;182(8):5041-51. https://doi. org/10.4049/jimmunol.0803192

30. Takada YK, Yu J, Shimoda M, Takada Y. Integrin binding to the trimeric interface of CD40L plays a critical role in CD40/CD40L signaling. J Immunol. 2019:203(5):1383-91. https://doi.org/10.4049/jimmunol.1801630.

31. Wabnitz GH, Köcher T, Lohneis P, Stober C, Konstandin MH, Funk B, et al. Costimulation induced phosphorylation of L-plastin facilitates surface transport of the T cell activation molecules CD69 and CD25. Eur J Immunol. 2007;37(3):649-62. https://doi.org/10.1002/eji.200636320.

32. Kamioka H, Tomono T, Fujita A, Onozato R, lijima M, Tsuchida S, et al. Moesin-mediated P-glycoprotein activation during snail-induced epithelialmesenchymal transition in lung cancer cells. J Pharm Sci. 2020;109(7):23028. https://doi.org/10.1016/j.xphs.2020.03.008.

33. Yano K, Okabe C, Fujii K, Kato Y, Ogihara T. Regulation of breast cancer resistance protein and $\mathrm{P}$-glycoprotein by ezrin, radixin and moesin in lung, intestinal and renal cancer cell lines. J Pharm Pharmacol. 2020:72:575-82.

34. Hoshi Y, Uchida Y, Kuroda T, Tachikawa M, Couraud PO, Suzuki T, et al. Distinct roles of ezrin, radixin and moesin in maintaining the plasma membrane localizations and functions of human blood-brain barrier transporters. J Cereb Blood Flow Metab. 2020;40(7):1533-45. https://doi. org/10.1177/0271678X19868880.

35. Kawase A, Inoue $Y$, Nakazaki S, Koizumi E, Iwaki M. Radixin knockdown improves the accumulation and efficiency of methotrexate in tumor cells. Oncol Rep. 2019;42(1):283-90. https://doi.org/10.3892/or.2019.7162.

\section{Publisher's Note}

Springer Nature remains neutral with regard to jurisdictional claims in published maps and institutional affiliations. 